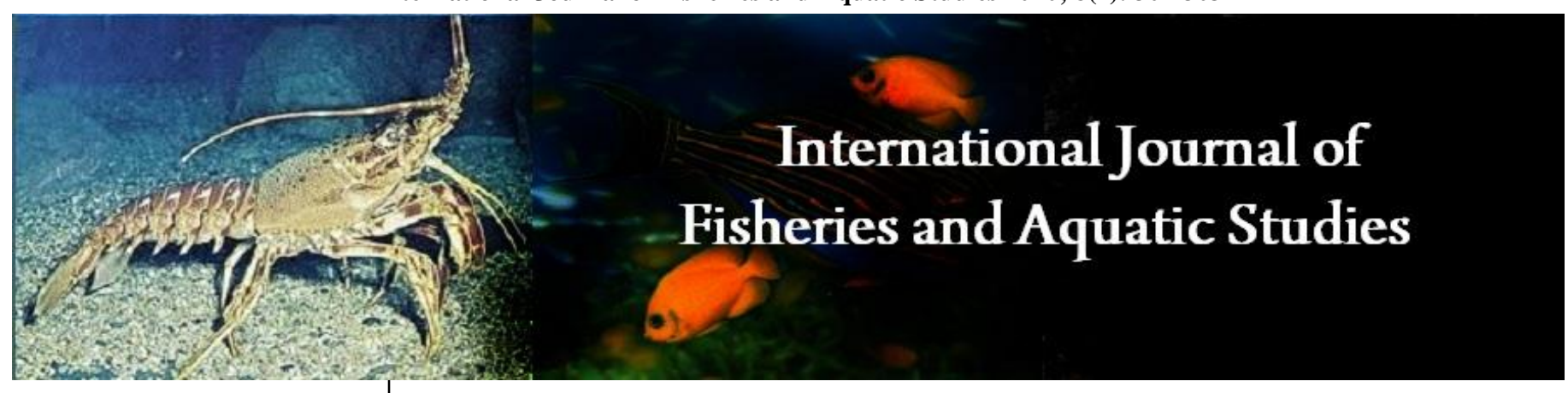

E-ISSN: 2347-5129

P-ISSN: 2394-0506

(ICV-Poland) Impact Value: 5.62

(GIF) Impact Factor: 0.549

IJFAS 2020; 8(4): 301-303

(C) 2020 IJFAS

www.fisheriesjournal.com

Received: 05-06-2020

Accepted: 30-07-2020

Mishra Surya Prakash

Department of Zoology, Ganpat

Sahai P.G. College Sultanpur,

Uttar Pradesh, India
Corresponding Author:

Mishra Surya Prakash

Department of Zoology, Ganpat

Sahai P.G. College Sultanpur,

Uttar Pradesh, India

\section{Food and feeding habit of Indian major carp Bhakur (Catla catla) from Meeranpur lake, Sultanpur, Uttar Pradesh}

\section{Mishra Surya Prakash}

DOI: $\underline{\text { https://doi.org/10.22271/fish.2020.v8.i4d.2286 }}$

\begin{abstract}
The growth of a fish is influenced by the quality and quantity of food materials available and consumed. Any variation in quality and quantity of food materials will affect the growth rate of the fish. These variations of natural food materials in a water body are under the influence of several abiotic and biotic factors. The gut content analysis provides the information on food components and feeding habit of fish which is an important aspect for fish culture. In the present study, the qualitative and quantitative analysis of gut content of Indian major carp Catla catla from Meeranpur lake of district Sultanpur, Uttar Pradesh, India, were conducted during August 2018 to July 2019. The results on gut content shows that qualitative changes in food component were not found but quantitative changes were observed during the investigation period. In the present study the gut content mainly consists of Crustaceans (33.58\%), Rotifers (18.74\%), Bacillariophyceae (16.07\%), Chlorophyceae (8.84\%), Protozoans (6.80\%), Myxophyceae (6.12\%), Aquatic Insects (4.86\%), Aquatic Plant materials (4.59\%), and Decayed Organic matter present in negligible amount $(0.41 \%)$ in Bhakur (Catla catla). The findings suggests that the experimental fish Bhakur (Catla catla) is mainly planktophagus and is more suitable for fresh water rich in planktons. The details have been discussed in this paper.
\end{abstract}

Keywords: Bhakur (Catla catla), food and feeding habit, gut contents, Meeranpur lake

\section{Introduction}

Food and Feeding habits of fishes are important factors for selection of fish for culture to avoid competition for food and live in association to utilize all the available food (Dewan and Saha, 1979) ${ }^{[4]}$. Bhakur (Catla catla) is one of the most preferred and rapid growing fish among the Indian major carps and it is accepted as a potential fresh water species in different parts of the world including India, Pakistan, Bangladesh and other southern Asian countries. The magnitude of fish population in a region is the function of food potentialities and are varies with the species, seasons, food availability, food preference, maturity stage and spawning season of the fish (Krishna, et al. 2016) ${ }^{[14]}$. Fishes have become adapted to a wide variety of food. The food of fry and fingerlings are generally different from that of the adult fish. Fishes are highly adaptable in their feeding habits and utilize the readily available food. The experimental fish Bhakur (Catla catla) are plankton feeder, they basically feeds on planktons and detritus material (Hora and Pillay, 1962) ${ }^{[7]}$.

The qualitative and quantitative food analysis of fish in their natural habitats enhances the understanding of the growth, abundance, productivity of water body (Nansimole, et al. 2014) ${ }^{[16]}$ and used to describe food habits and feeding patterns of fishes (Ekpo, et al. 2014) ${ }^{[6]}$. The feeding intensity of mature fish decreases during the spawning season as compared to the nonspawning season. The relationship between the food component and fish is essential for the production and exploitation of the fish stocks (Sunder, et al. 1990) ${ }^{[20]}$. It is not possible to collect sufficient information of food and feeding habit of fish in their natural habitat without studying its gut contents (Hyslop, 1980) ${ }^{[10]}$. The food and feeding habit of different fish varies from month to month or season to season due to changes in the availability of food components. Studies on the food and feeding habit of different fishes have been made by many

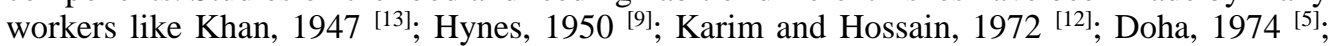

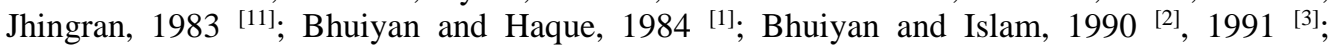
Hossain, et al. $1991^{[8]}$; and Pandit et al. $2018^{[18]}$. 
The thorough knowledge of food and feeding habits of fishes provides keys to select such species of fish for culture and produce an optimum yield by utilizing all the available potential food of the water bodies without any competition. The collection of much information about food and feeding habit of fish is necessary for successful fish culture. The present study deals with the food and feeding habit of Bhakur (Catla catla), observe the gut contents and the relationship between weight of gut and the weight of the fish. The present study will be useful in determining the stocking density on the basis of natural food available in the lake.

\section{Materials and Methods}

The specimens of experimental fish Bhakur (Catla catla) were collected from Meeranpur lakes of district Sultanpur during August 2018 to July 2019. The month wise collection and investigation were made to study the food and feeding habit of the fish. The specimens were collected with the help of fisherman. Just after collection $10 \%$ formalin solution was injected in to the gut of all the fishes in order to stop digestion of food items. All the experiments were carried out in the laboratory of the Post Graduate Department of Zoology, Ganpat Sahai P.G. College Sultanpur, Uttar Pradesh.

The feeding intensity was assessed by visual estimation volumetrically (Pillay, 1952) ${ }^{[19]}$ based on the distension of the gut and the quantity of food contained in it. The various gut conditions based on degree of fullness are expressed as gorged, full, $3 / 4$ full, 1/2 full, 1/4 full, trace and empty by occurrence method (Hynes, 1950) ${ }^{[9]}$. The gut was then cut open and contents were analysed under binocular microscope for the food composition, preference and relative importance of various food items following the volumetric estimation method (Pillay, 1952) ${ }^{[19]}$. For evaluating the relative importance of food items, the index of preponderance (Natarajan and Jhingran, 1961) ${ }^{[17]}$ was obtained by using following formula:

\section{Index of preponderance $=\frac{\mathrm{V} 1 \times 01}{\Sigma \mathrm{V} 1 \times 01} \times 100$}

Where, $\mathrm{V}_{1}=$ Volume of percentage

$\mathrm{O}_{1}=$ Occurrence of percentage

\section{Results and Discussion}

The analysis of food and feeding habits of 144 samples of fish Bhakur (Catla catla) are illustrated in Table 1 and 2. Table 1 illustrates the fullness and emptiness of gut of fish and Table 2 illustrates the Grading of various food items of gut contents of fish Bhakur (Catla catla) during investigation period from August 2018 to July 2019.

The gut of 144 fishes were analyzed of which $62.86 \%$ contained food and the rest $37.14 \%$ were without food, which varies from month to month. The highest percentage of empty gut was in the month of June $2019(58.68 \%)$ and the lowest percentage of empty gut was in the month of August 2018
(23.68\%). The highest percentage of full gut was found in the month of August 2018 (76.32\%) and the lowest percentage of full gut was found in the month of June 2019 (41.32\%) (Table 1). The condition of feeding was also related to maturity of fish. The immature fishes were found to feed with almost equal intensity throughout the year. These findings clearly indicated that the feeding intensity of juvenile fishes is more. Similar findings has been observed by Khan, $1947^{\text {[13]; Dewan }}$ and Saha, $1979^{[4]}$ and Kumar, et al. $2015^{[15]}$.

Table 1: Feeding activity of Bhakur (Catla catla) based on the number of fish, percentage of fullness and emptiness of gut during August 2018 to July 2019

\begin{tabular}{|c|c|c|c|}
\hline Months & $\begin{array}{c}\text { Number of } \\
\text { fish }\end{array}$ & $\begin{array}{c}\text { Percentage of gut } \\
\text { fullness }\end{array}$ & $\begin{array}{c}\text { Percentage of gut } \\
\text { emptiness }\end{array}$ \\
\hline AUG & 10 & 76.32 & 23.68 \\
\hline SEP & 14 & 75.16 & 24.84 \\
\hline OCT & 13 & 72.38 & 27.62 \\
\hline NOV & 15 & 73.27 & 26.73 \\
\hline DEC & 11 & 56.18 & 43.82 \\
\hline JAN & 16 & 44.26 & 55.74 \\
\hline FEB & 14 & 68.42 & 31.58 \\
\hline MAR & 12 & 69.84 & 30.16 \\
\hline APR & 10 & 67.32 & 32.68 \\
\hline MAY & 09 & 61.24 & 38.76 \\
\hline JUN & 08 & 41.32 & 58.68 \\
\hline JUL & 12 & 48.56 & 51.44 \\
\hline Mean \pm SD & $12 \pm 2.44$ & $62.86 \pm 12.41$ & $37.14 \pm 12.41$ \\
\hline
\end{tabular}

The Percentage composition (by Volume and Occurrence), Preponderance and Grading of the various food items found in the gut content of Bhakur (Catla catla) are enumerated in Table 2. The findings revealed that the food items found in the gut of Bhakur (Catla catla) consists of Aquatic plant materials, Chlorophyceae, Bacillariophyceae, Myxophyceae, Protozoans, Rotifers, Crustaceans, Aquatic insects and Decayed organic matter.

The Crustaceans (Cladocerans and Copepods) formed the main item of gut contents forming $19.36 \%$ by volume and $22.65 \%$ by occurrence in the gut contents of Bhakur (Catla catla). Rotifers formed the next important food items in the gut contents forming $16.34 \%$ by volume and $14.98 \%$ by occurrence. Bacillariophyceae (diatoms) is another important food items in the gut contents forming $16.68 \%$ by volume and $12.58 \%$ by occurrence. Chlorophyceae (green algae and desmids) formed a part of gut by constituting $9.42 \%$ by volume and $12.26 \%$ by occurrence. The Myxophyceae (bluegreen algae) in the gut contents of Bhakur (Catla catla) were $9.12 \%$ by volume and $8.76 \%$ by occurrence. The percentage of Protozoans in the gut contents were $13.57 \%$ by volume and $6.54 \%$ by occurrence. Aquatic insects and their instars formed $8.74 \%$ by volume and $7.26 \%$ by occurrence. The remnants of macrovegetation were represented by $5.36 \%$ by volume and $11.19 \%$ by occurrence. Decayed and semidecayed organic matter constituted only $1.41 \%$ by volume and $3.78 \%$ by occurrence.

Table 2: Grading of various food items of gut contents of Bhakur (Catla catla), collected during August 2018 to July 2019 from Meeranpur Lake of district Sultanpur (U.P.)

\begin{tabular}{|c|c|c|c|c|c|}
\hline \multirow{2}{*}{ Food Items } & \multicolumn{2}{|c|}{ \% Composition of food items } & \multirow[b]{2}{*}{$\mathbf{V}_{1} \times \mathbf{O}_{1}$} & \multirow{2}{*}{ Preponderance } & \multirow{2}{*}{ Grading } \\
\hline & Volume $\left(V_{1}\right)$ & Occurrence $\left(\mathrm{O}_{1}\right)$ & & & \\
\hline Aquatic Plant materials & 5.36 & 11.19 & 59.978 & 4.59 & VIII \\
\hline Chlorophyceae & 9.42 & 12.26 & 115.489 & 8.84 & IV \\
\hline Bacillariophyceae & 16.68 & 12.58 & 209.834 & 16.07 & III \\
\hline Myxophyceae & 9.12 & 8.76 & 79.891 & 6.12 & VI \\
\hline
\end{tabular}




\begin{tabular}{|c|c|c|c|c|c|}
\hline Rotifers & 16.34 & 14.98 & 244.773 & 18.74 & II \\
\hline Protozoans & 13.57 & 6.54 & 88.748 & 6.80 & V \\
\hline Crustaceans & 19.36 & 22.65 & 438.504 & 33.58 & I \\
\hline Aquatic Insects & 8.74 & 7.26 & 63.452 & 4.86 & VII \\
\hline Decayed Organic matter & 1.41 & 3.78 & 5.330 & 0.41 & IX \\
\hline & & & $\sum \mathrm{V}_{1} \times \mathrm{O}_{1}=1306$ & & \\
\hline
\end{tabular}

From the present study on the food and feeding habit of Indian major carp Bhakur (Catla catla), it appears that the basic food of this fish in Meeranpur lake is mainly comprised of Crustaceans (33.58\%), Rotifers (18.74\%), Bacillariophyceae (16.07\%), Chlorophyceae (8.84\%), Protozoans (6.80\%), Myxophyceae (6.12\%), Aquatic insects $(4.86 \%)$ and Aquatic plant materials $(4.59 \%)$. The decayed organic matter formed a negligible amount $(0.41 \%)$ in the gut content of Bhakur (Catla catla).

Earlier, Hora and Pillay (1962) ${ }^{[7]}$ assigned Bhakur (Catla catla) as a plankton and detritus feeder and reported it to consume primarily phytoplankton and zooplankton, decayed micro-vegetation and detritus. However, reported that the adult Bhakur (Catla catla) feeds mainly on algae, crustaceans, some plants, rotifers and aquatic insects and hence he categorized the same as a plankton feeder.

\section{Conclusion}

The analysis of gut contents showed the availability and preference of food items by the fish helps to find out the feeding habit of fish and accordingly fisheries management in the water body. In the present study zooplanktons was the dominant food component followed by phytoplanktons and aquatic plant materials in fish gut. On the basis of these observations, it can be concluded that the experimental fish Bhakur (Catla catla) is plankton feeder and feeds primarily on zooplanktons. This result agrees with Kumar et al. (2015) ${ }^{[15]}$ and Pandit et al. (2018) ${ }^{[18]}$.

\section{References}

1. Bhuiyan AS, Haque MS. Studies on the seasonal changes of food habit of Mystus vittatus (Bloch) (Bagridae: Cypriniformes). Proc. 4th. Nat. Zool. Conf. Bangladesh, 1984, 88-91.

2. Bhuiyan AS, Islam MN. Seasonal variation in the percentage composition of the food of Xenentodon cancila. Univ. J Zool. Rajshahi Univ. 1990; 7:33-34.

3. Bhuiyan AS, Islam MN. Observation on the food and feeding habit of Ompok pabda (Ham.) from the river Padma (Siluridae: Cypriniformes). Pakistan J Zool. 1991; 23(1):75-77.

4. Dewan S, Shaha SN. Food and feeding habit of Tilapia nilotica (L) (Perciformes: Chichlidae). II. Diet and seasonal patterns of feeding. Bangladesh J Zool. 1979; 7(2):75-80.

5. Doha S. Investigation in to the biology of the goby Glossogobius giuris (Ham. Buch.) (Perciformes: Gobidae). Bangladesh J Zool. 1974; 2 (2): 95-106.

6. Ekpo IE, Mandu A, Essien J, Joseph NN. Food and feeding habits and condition factor of fish species in Qua Iboe River estuary, Akwa Ibom State, Southeastern Nigeria. Int. J Fish. Aquatic Studies. 2014; 2(2):38-46.

7. Hora SL, Pillay TVR. Hand book on fish culture in the Indo-Pacific region. FAO Fisheries Biological Technical Paper. 1962; 14:204.

8. Hossain MA, Rahman MH, Parween S. Notes on the length-weight relationship of Lepidocephalus guntea. Bangladesh J Zool. 1991; 19(1):145-146.
9. Hynes HNB. The food of fresh water stickleback (Gasterosteus aculeatus and Pygosteus pungitius) with a review of methods used in studies of the food of fishes. $\mathbf{J}$ Anim. Ecol. 1950; 19:26-28.

10. Hyslop EJ. Stomach Contents Analysis: A review of methods and their application J Fish. Biol. 1980; 17:411429.

11. Jhingran VG. Fish and Fisheries of India (Revised and enlarged 2nd ed.). Hindustan Publishing Corporation (India) Delhi, 1983, 645.

12. Karim MA, Hossain A. Studies on the biology of Mastacembelus pancalus (Spiny eel) in artificial pond. Part-II. Sexual maturity and fecundity. Bangladesh J Biol. And Agri. Sci. 1972; 1(2):15-18.

13. Khan H. Development of fisheries in the Punjab. III. Culture and Propagation of indigenous species of fish. Indian Farming. 1947; 8(9):147-153.

14. Krishna PV, Panchakshari V, Prabhavathi K. Feeding Habits and Stomach Contents of Asian sea bass Lates calcarifer from Nizampatnam Coast, International Journal of Advanced Research. 2016; 4:168-172.

15. Kumar L, Sharma BK, Sharma SK, Upadhyay B, Mishra V. Food and Feeding Habits of Catla catla (Ham.) from Lake Udai Sagar, Udaipur. Int. J Fauna and Biol. Studies. 2015; 2(5):6-8.

16. Nansimole A, Sruthi, Gayathri TV, Lekshmi S, Balsubramaniam NK, Radhkrishnan. Studies on morphometry feeding biology and sex ratio of Saurida undosquamis (Richardson, 1884) from Neenda-Kara area, Kollam, south west coast of India. Indian J Sci. Res. 2014; 5(2):51-58.

17. Natarajan AV, Jhingran AG. Index of preponderance- a method of grading the food elements in the stomach analysis of fishes. Indian J Fish. 1962; 8(1):54-59.

18. Pandit SN, Kumar A, Yadav SN. Kiranlata: Food and Feeding Habit of Cirrhina mrigala in ponds of Singheshwar Madhepura; Bihar. Proc. Zool. Soc. India. 2018; 17(1):31-35.

19. Pillay TVR. Studies of food and feeding habits and alimentary canal of the grey mullet, Mugil tade Forsk, Proc. Nat. Inst. Sci. India. 1952; 19:777-827.

20. Sunder S, Kumar K, Raina HS. Food and Feeding Habit and length-weight relationship of Cyprinus carpio specularis L. of Dal Lake, Kashmir. Indian J Fish. 1990; 31(1):90-99. 